\title{
The Curing Kinetics of E-Glass Fiber/Epoxy Resin Prepreg and the Bending Properties of Its Products
}

\author{
Lvtao Zhu ${ }^{1,2, *}$, Zhenxing Wang ${ }^{1}$, Mahfuz Bin Rahman ${ }^{1}$, Wei Shen ${ }^{2}$ and Chengyan Zhu ${ }^{1}$ \\ 1 College of Textile Science and Engineering (International Institute of Silk), Zhejiang Sci-Tech University, \\ Hangzhou 310018, China; zhenxing@zstu.email.cn (Z.W.); mahfuz.zstu@gmail.com (M.B.R.); \\ cyzhu@zstu.edu.cn (C.Z.) \\ 2 Shaoxing Baojing Composite Materials Co., Ltd., Shaoxing 312000, China; shenw@jinggonggroup.com \\ * Correspondence: zhult@zstu.edu.cn; Tel.: +86-151-5888-8425
}

Citation: Zhu, L.; Wang, Z.;

Rahman, M.B.; Shen, W.; Zhu, C.

The Curing Kinetics of E-Glass

Fiber/Epoxy Resin Prepreg and the Bending Properties of Its Products.

Materials 2021, 14, 4673.

https://doi.org/10.3390/ma14164673

Academic Editor: Angelo

Marcello Tarantino

Received: 22 July 2021

Accepted: 9 August 2021

Published: 19 August 2021

Publisher's Note: MDPI stays neutral with regard to jurisdictional claims in published maps and institutional affiliations.

Copyright: (c) 2021 by the authors. Licensee MDPI, Basel, Switzerland. This article is an open access article distributed under the terms and conditions of the Creative Commons Attribution (CC BY) license (https:// creativecommons.org/licenses/by/ $4.0 /)$.

\begin{abstract}
The curing kinetics can influence the final macroscopic properties, particularly the threepoint bending of the fiber-reinforced composite materials. In this research, the curing kinetics of commercially available glass fiber/epoxy resin prepregs were studied by non-isothermal differential scanning calorimetry (DSC). The curing kinetic parameters were obtained by fitting and the apparent activation energy $E_{a}$ of the prepreg, the pre-exponent factor, and the reaction order value obtained. A phenomenological $n$ th-order curing reaction kinetic model was established according to Kissinger equation and Crane equation. Furthermore, the optimal curing temperature of the prepregs was obtained by the T- $\beta$ extrapolation method. A vacuum hot pressing technique was applied to prepare composite laminates. The pre-curing, curing, and post-curing temperatures were 116,130 , and $153^{\circ} \mathrm{C}$ respectively. In addition, three-point bending was used to test the specimens' fracture behavior, and the surface morphology was analyzed. The results show that the differences in the mechanical properties of the samples are relatively small, indicating that the process settings are reasonable.
\end{abstract}

Keywords: prepreg; glass fiber/epoxy resin; curing kinetics; bending properties

\section{Introduction}

Glass fiber reinforced composites have remained interesting for academia as well as industry due to their outstanding properties, i.e., lightweight, fatigue resistance, corrosion resistance, high specific strength, and easy manufacturing techniques, as well as reasonable cost compared to other fiber-reinforced composites [1,2]. They have been widely used in many areas such as aerospace, marine, automotive, medical, sports, machine tools, and for several other structures [3]. E-glass fiber/epoxy resin prepreg is an intermediate for the manufacture of composite materials [4]. It is a composition obtained by impregnating E-glass fiber or fabric with epoxy resin. The epoxy resin in a B-level semi-cured state can be cured under a specific temperature and pressure to obtain composite products. This manufacturing method can significantly improve production efficiency but has high requirements for the rationality of the curing process design [5]. This is mainly reflected in the setting of process parameters. Setting reasonable process parameters is the key to obtaining high-quality products.

The study of curing kinetics is an important basis for designing curing conditions [6,7]. At present, the curing kinetics of resin matrix composites are mainly based on the mechanism method and phenomenological method $[8,9]$. The mechanism method regards the overall reaction as the sum of each elementary reaction and studies each elementary reaction and the related effects. This can accurately describe the curing kinetics, but it is difficult to calculate and model [10]. The phenomenological method is semi-empirical curing, i.e., the kinetic model. It mainly studies the overall reaction and obtains the kinetic parameters through a mathematical simulation from the empirical equation. It has the advantage of being simple and intuitive, so it is widely used. Cai et al. used differential 
scanning calorimetry under dynamic as well as isothermal conditions to study the curing kinetics of two epoxy resin/flexible amine systems and established a phenomenological curing kinetic model. The experimental results have consistency with the predicted results of the model; thus, these models can be used to describe the curing phenomenon of the resin well [11]. Liu et al. investigated the phenomenological curing model of epoxy resin for prediction of the degree of the cure based on an autocatalytic cure kinetic model and a new modified phenomenological curing model based on Olivier's model, and they showed that the modified Olivier's model is simple, easy to use and more accurate [12]. The curing kinetics has a significant influence on the macroscopic mechanical properties of composite materials [13].

The three-point bending experiment is considered as one of the important and most extensively used tests in measuring the mechanical properties of composite material [14]. Mouzakis et al. used a three-point bending test to study the changes in the bending strength of polyester/glass fiber reinforced composite materials (GFRPC) under the combined effects of temperature, humidity, and ultraviolet radiation [15]. Ren et al. prepared a modified fiber-reinforced phthalonitrile-based resin composite laminate and tested its bending strength through a three-point bending test [16]. Jariwala et al. studied the influence of fiber structure on the mechanical properties of E glass fiber reinforced composites, and the bending strength was tested by a three-point bending experiment [17]. Shin et al. studied the optimal conditions of glass fiber/epoxy resin composites based on the mixing ratio of the two epoxy resin matrices. Three-point bending was used to test the bending performance and finally obtained when the epoxy resin mixing ratio is $1: 1$, the mechanical performance of the composite material is the best [18]. Therefore, we choose a three-point bending experiment to test the sample's mechanical properties in our research.

As the curing process parameters have a crucial influence on the quality of composite products, we focused on the curing kinetics of epoxy resin. The curing kinetic parameters were obtained by non-isothermal differential scanning calorimetry, the curing kinetic model of the resin was established, and the optimal curing temperature parameters of the resin were obtained by the T- $\beta$ extrapolation method. Further, the composite laminates were prepared by the vacuum hot pressing process, and three-point bending was used to test the difference in mechanical properties between different samples. This method is of great significance to guide the actual production; it can quickly obtain the best curing temperature range of the resin and quickly check its quality.

\section{Materials and Methods}

\subsection{Materials}

The sample used was a prepreg (composed of ER468-2400 E-glass fiber and 7901 DNK toughened epoxy resin) purchased from Weihai Guangwei Composite Material Co., Ltd., Weihai, China. The 7901 DNK is a resin with good curing and process properties obtained after modification by a variety of epoxy resins, mainly including DGEBA and BDGE. IPDA is the main curing agent for this resin. Their structure are shown in the Figure 1. The main properties of prepreg are shown in Table 1.

Table 1. Main properties of prepreg.

\begin{tabular}{ccc}
\hline Physical Properties & Unit & Value \\
\hline The weight of prepreg per unit area & $\mathrm{g} / \mathrm{m}^{2}$ & $2352 \pm 5 \%$ \\
\hline Fiber weight per unit area & $\mathrm{g} / \mathrm{m}^{2}$ & $1600 \pm 5 \%$ \\
\hline Single-layer thickness & $\mathrm{mm}$ & $1.2 \pm 0.1$ \\
\hline Resin content & $\%$ & $32.0 \pm 3.0$ \\
\hline Volatile content & $\%$ & $\leq 1.0$ \\
\hline
\end{tabular}


(a)<smiles>CC(C)(c1ccc(OCC2CO2)cc1)c1ccc(OCC2CO2)cc1</smiles>

(b)<smiles>C(CCOCC1CO1)COCC1CO1</smiles>

(BDGE)

(c)<smiles>CC1(C)CC(N)CC(C)(C)C1</smiles>

Figure 1. Chemical structure formula of (a) DGEBA, (b) BDGE and (c) IPDA.

\subsection{Manufacturing of Composite Laminates}

The prepregs were cut to $250 \times 300 \mathrm{~mm}$ and laid up to $15 \mathrm{~mm}$ on the mold by hand, laying 5 groups of the same thickness to detect the difference in mechanical properties after curing. After being laid up, vacuum treatment was used to eliminate minute bubbles that may occur during the layup process so that the good mechanical properties of the laminate could be obtained. Finally, the laminates were put into a vacuum autoclave for curing using 1.33 MPa pressure. The curing temperature curve of the prepreg was set according to the DSC test results.

\subsection{Three-Point Bending Test}

A sample of $270 \times 13 \times 15 \mathrm{~mm}$ was cut out from the middle of each group of laminates, and a total of five samples were obtained. The samples were placed on a universal testing machine (M.T.S. landmark 370.10, Eden Prairie, MN, USA) to test the three-point bending performance. The span was set to $240 \mathrm{~mm}$ (shown in Figure 2), and the upper indenter remained stationary. The lower indenter is loaded upwards at a speed of $10 \mathrm{~mm} / \mathrm{min}$ so that the sample is stressed at three points, and finally, a fracture occurs in the middle of the sample. The test was carried out under the conditions of a temperature of $25^{\circ} \mathrm{C}$ and a humidity of $50 \%$.
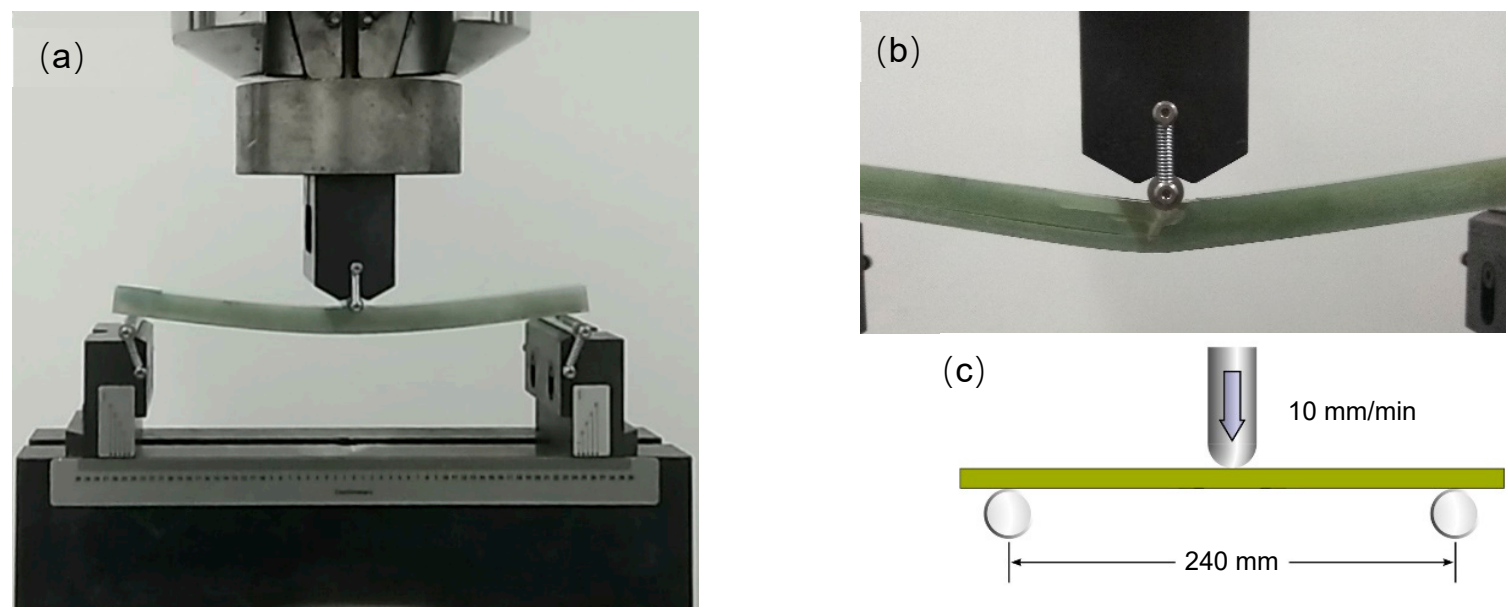

(c)

$10 \mathrm{~mm} / \mathrm{min}$

Figure 2. Three-point bending test diagrams: (a) specimen under bending load; (b) specimen fracture closer view; (c) schematic diagram. 


\subsection{Characterization}

DSC 25 (T.A. Instruments, New Castle, DE, USA) was used for calorimetric measurements for dynamic DSC scans. Three samples were heated from 25 to $250{ }^{\circ} \mathrm{C}$ at different heating rates, i.e., 5,10 , and $15{ }^{\circ} \mathrm{C} / \mathrm{min}$, with approximate sample weights of $3.50 \mathrm{mg}$ under an $\mathrm{N}_{2}$ purge at $50 \mathrm{~mL} / \mathrm{min}$. The DSC was used to determine the heat released while curing the specimen under non-isothermal conditions. The thermal weight loss of the sample was determined using PerkinElmer PYRIS 1 thermogravimetric analysis (TGA). Then, 5-8 mg of the sample was heated from 25 to $1000{ }^{\circ} \mathrm{C}$ at a rate of $10^{\circ} \mathrm{C} / \mathrm{min}$ under a nitrogen purge of $30 \mathrm{~mL} / \mathrm{min}$. A scanning electron microscope (SEM, COXEM, Daejeon, Korea) operating at $10 \mathrm{kV}$ was used to observe the SEM images surface morphology of the fractured surface of the composite laminates.

\section{Results and Discussion}

\subsection{Thermogravimetric Analysis}

The TGA curve of the epoxy resin sample is shown in Figure 3. The weight loss process of the sample is roughly divided into three processes: the first stage is before $350{ }^{\circ} \mathrm{C}$, the weight loss rate is about $5 \%$; the second stage $\left(350-550{ }^{\circ} \mathrm{C}\right)$ has the fastest weight loss, which is about $85 \%$ lower; in the third stage $\left(550-1000{ }^{\circ} \mathrm{C}\right)$, the mass loss of the sample tends to be stable, with a loss of about $2.88 \%$. The initial weight loss $(\leq 5 \%)$ was attributed to the removal of water molecules and some small organic compounds from the resin [19]. The temperature at $5 \%$ weight loss $\left(T_{d 5}\right)$ was $350^{\circ} \mathrm{C}$. The thermal decomposition temperature at $30 \%$ weight loss $\left(T_{d 30}\right)$ was $405{ }^{\circ} \mathrm{C}$, far more significant than any service temperature proposed for this resin. The peak degradation temperature $\left(T_{\text {deg }}\right)$ was determined by differentiating the degradation curve, as shown in Figure $3 . T_{\text {deg }}$ exhibited a single-step degradation profile which suggests that the sharp decomposition of the crosslinked polymer network. The heating program was designed to obtain the thermal degradation temperature of the epoxy resin sample to ensure that the sample will not be thermally degraded during the DSC test, so the maximum temperature of the DSC test was set to $250{ }^{\circ} \mathrm{C}$.

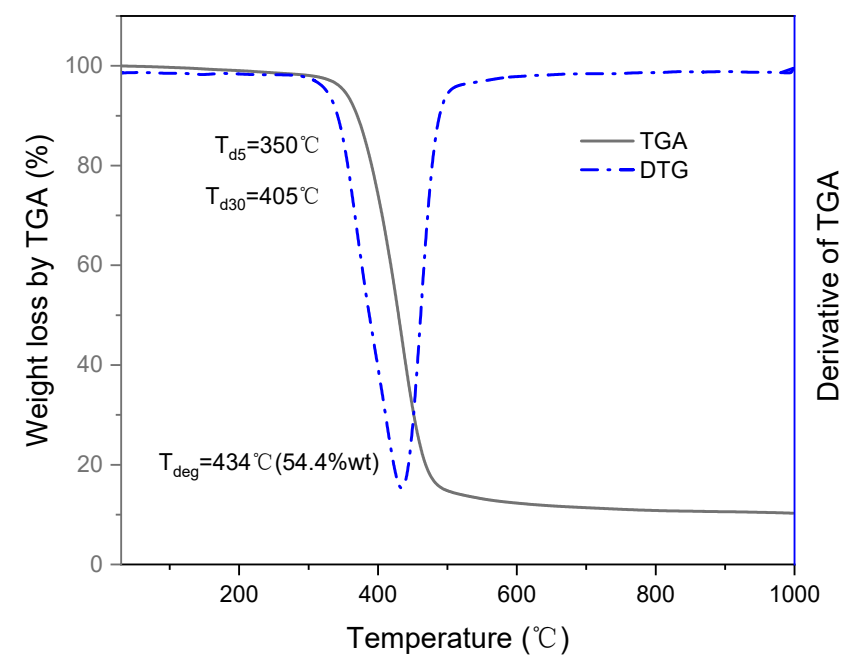

Figure 3. TGA graph of 7901 DNK toughened epoxy resin.

\subsection{DSC Curve Analysis}

The DSC test results of the prepreg under different heating rates $(\beta)$ are shown in Figure 4. The DSC curves of the prepreg under different heating rates all showed a single exothermic peak, which indicated that the curing reaction was completed in one step. This is because the heat flow rate is directly proportional to the heating rate. As the heating rate increases, the start temperature $\left(T_{i}\right)$, peak temperature $\left(T_{p}\right)$, and end temperature $\left(T_{f}\right)$ of 
the curing reaction also increase. As the heating rate increases, the heating effect per unit time increases, and the thermal inertia and temperature difference become larger [20].

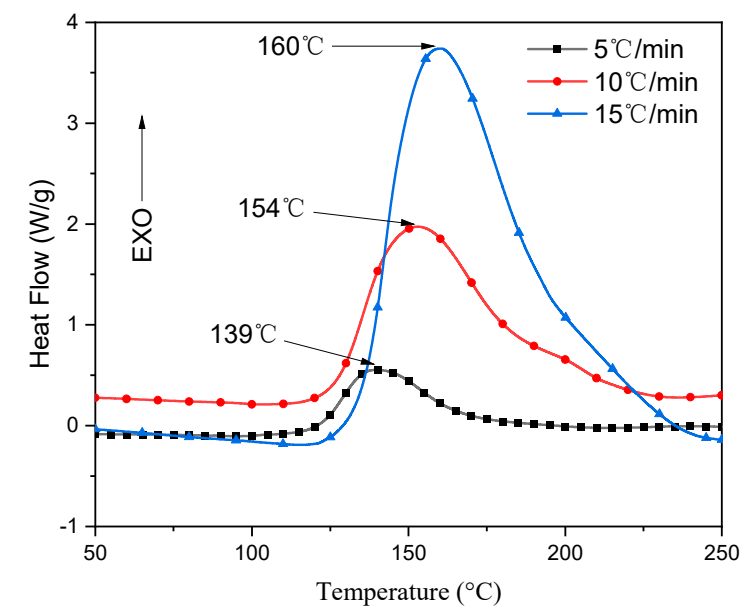

Figure 4. DSC curve for the $7901 \mathrm{DNK}$ toughened epoxy resin at different heating rates of $5{ }^{\circ} \mathrm{C} / \mathrm{min}$, $10^{\circ} \mathrm{C} / \mathrm{min}, 15^{\circ} \mathrm{C} / \mathrm{min}$ in $\mathrm{N}_{2}$ atmosphere.

The curing process of thermosetting resin is complex, involves a series of chemical reactions, and finally transforms the low molecular weight monomer into the macromolecular crosslinked network [13]. Under normal circumstances, this process is accompanied by a change in heat. The rate of heat generated was plotted against time, and their integration provided the amount of heat released. According to the curve shown in Figure 4, total enthalpy was calculated by the area under the exothermic curve of the DSC. This is an essential physical quantity representing the total heat released during the curing reaction, as shown in Table 2-the amount of heat released by the curing reaction increases as the heating rate increases.

Table 2. Thermodynamic parameters of prepreg at different heating rates.

\begin{tabular}{ccccc}
\hline \multirow{2}{*}{$/\left({ }^{\circ} \mathbf{C} \cdot \mathbf{m i n}^{-1}\right)$} & \multicolumn{3}{c}{ Cure Temperature $\left({ }^{\circ} \mathbf{C}\right)$} & \multirow{2}{*}{$\boldsymbol{H}_{\text {tot }} /\left(\mathbf{J} \cdot \mathbf{g}^{-\mathbf{1})}\right.$} \\
\cline { 2 - 4 } & $\boldsymbol{T}_{\boldsymbol{i}} /{ }^{\circ} \mathbf{C}$ & $\boldsymbol{T}_{\boldsymbol{p}} /{ }^{\circ} \mathbf{C}$ & $\boldsymbol{T}_{\boldsymbol{f}} /{ }^{\circ} \mathbf{C}$ & \\
\hline 5 & 122 & 139 & 169 & 257 \\
\hline 10 & 128 & 154 & 192 & 499 \\
\hline 15 & 135 & 160 & 205 & 780 \\
\hline
\end{tabular}

The curing of the epoxy resin is a staged process; there are usually three stages of curing, commonly referred to as pre-cure, cure, and post-cure, and their respective temperatures obtained on the DSC curves are termed as initial temperature $\left(T_{i}\right)$, peak temperature $\left(T_{p}\right)$, and final temperature $\left(T_{f}\right)$ [21], as shown in Figure 5; the temperature at which the curing reaction occurs is linearly related to the heating rate. So, the curing process temperature is usually determined by extrapolation. According to the T- $\beta$ extrapolated curve, when $\beta$ is zero, the theoretical gel temperature $\left(T_{i}^{*}\right)$, theoretical curing temperature $\left(T_{p}^{*}\right)$, and theoretical post-treatment temperature $\left(T_{f}^{*}\right)$ of the prepreg is 116,130 , and $153{ }^{\circ} \mathrm{C}$, respectively. That is to say; the theoretically reasonable curing process is to heat the prepreg to $116^{\circ} \mathrm{C}$. The viscosity of the resin will gradually decrease during this heating process, which is conducive to the resin infiltration of the reinforcing fibers; then the temperature is increased to $130^{\circ} \mathrm{C}$, the resin is crosslinking, and curing occurs at this temperature; finally, keep it at $153^{\circ} \mathrm{C}$ for a period of time to completely cure the resin. 


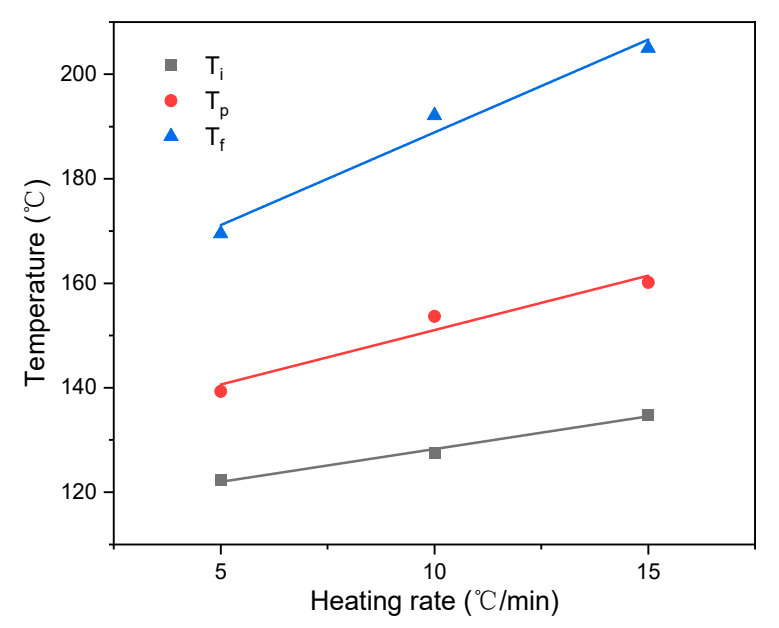

Figure 5. Extrapolation curves of the curing temperature.

\subsection{Curing Kinetics}

The epoxy cure kinetics are well represented by the phenomenological models. It is intuitive and straightforward, does not require a large amount of experimental data. The "degree of cure" is the measure of the chemical reactions (bond exchanges) that occurred during the curing process of the resin, and often it is the true representative of crosslinking density or molecular weight $[22,23]$. The degree of cure, $\alpha$, is determined by Equation (1) [24]:

$$
\alpha=\frac{H(t)}{H_{t o t}}
$$

where $H(t)$ is the heat of reaction at time $t$, and $H_{t o t}$ is the total heat of the reaction. The relationship between the degree of curing of the resin sample and the temperature is shown in Figure 6. As the heating rate increases, the temperature required for the resin to reach the same degree of curing continues to increase. This is mainly because the reaction rate increases with the increase of the heating rate, resulting in a faster increase in the system's viscosity. Part of the monomers is too late to react or cannot diffuse into the gel system in time, and the resulting temperature gradient increases, resulting in a decrease in the curing of the system during the diffusion phase at the same temperature [20].

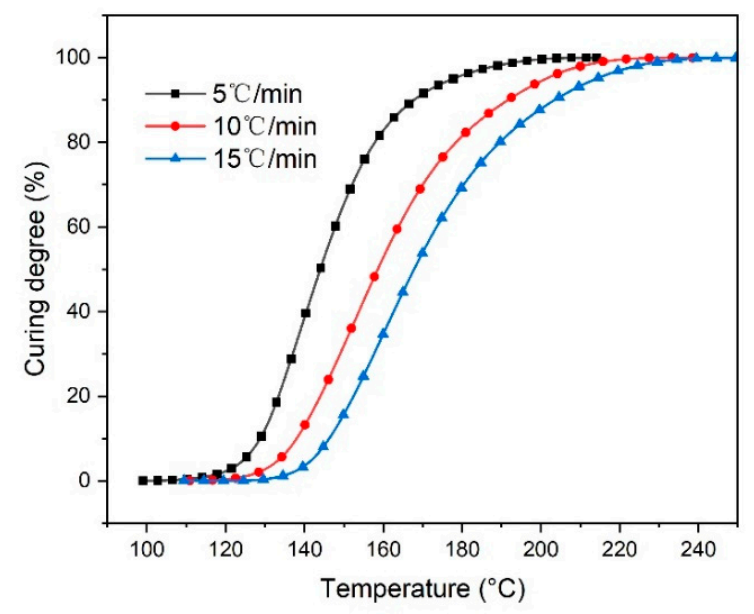

Figure 6. Curves of the curing degree temperature.

The rate of the kinetics process in kinetic analysis can be described by Equation (2) [25]:

$$
\frac{d \alpha}{d t}=K(T) f(\alpha)
$$


where $K(T)$ is the reaction rate constant (temperature-dependent), and $f(\alpha)$ describes the phenomenological reaction model. $K(T)$ can be mathematically presented according to the Arrhenius relationship.

$$
K(T)=A \exp \left(-\frac{E_{a}}{R T}\right)
$$

where $A$ is the pre-exponential factor, $E_{a}$ is the activation energy, and $R$ is the universal gas constant.

Comment model for $f(\alpha)$ is the $n$ th-order model, provided in Equation (4) [26]:

$$
f(\alpha)=(1-\alpha)^{n}
$$

Combination of Equations (2)-(4) results in the final kinetic expression provided in Equation (5):

$$
\frac{d \alpha}{d t}=A \exp \left(\frac{-E_{a}}{R T}\right) \cdot(1-\alpha)^{n}
$$

During the dynamic heating process of prepreg, the curing rate is a function of temperature and curing degree. A common technique for evaluating these data is the Kissinger method, which can be used to determine the activation energy of the curing reaction $[27,28]$, as presented in Equation (6):

$$
\ln \left(\frac{\beta}{T_{p}^{2}}\right)=\ln \left(\frac{A R}{E_{a}}\right)-\frac{E_{a}}{R T_{p}}
$$

The fitting the linear relationship between $\ln \left(\frac{\beta}{T_{p}^{2}}\right)$ versus $\frac{1}{T_{p}}$ can provide value of apparent activation energy $E_{a}$, the pre-exponential factor A through the intercept. The reaction order $n$ can be calculated according to the Crane Equation [29,30].

$$
\frac{d(\ln \beta)}{d\left(\frac{1}{T_{p}}\right)}=-\frac{E_{a}}{n R}
$$

According to the data in Table 3, using $\ln \left(\frac{\beta}{T_{p}^{2}}\right)$ and $\frac{1}{T_{p}}$ to plot, and then perform linear fitting, the obtained epoxy resin curing reaction activation energy and pre-finger factor fitting curve is shown in Figure 7a. The slope of the fitted curve is -8.41 , and the intercept is 9.95. The Adj. R-square is 0.9933 , indicating a good linear correlation. Substituting the obtained slope and intercept into Equation 6 can be calculated: $E_{a}=69.95 \mathrm{~kJ} / \mathrm{mol}$, $\mathrm{A}=1.76 \times 10^{5} \mathrm{~min}^{-1}$.

Use $\ln \beta$ and $\frac{1}{T_{p}}$ to the plot, and then perform the linear fitting. The reaction order fitting curve of the epoxy resin curing reaction is shown in Figure $7 \mathrm{~b}$. The slope of the fitted curve is -9.26 , the intercept is 24.04 , and the Adj. R-square is 0.9944 , indicating a good linear correlation. Substituting $E_{a}$ and the slope and intercept of this curve into Equation (7) can find $n=0.91$.

Substituting the obtained curing kinetic parameters $E_{a}, A, n$ into the $n$ th-order curing kinetic Equation (5) and integrating them, the following Equation (8) can be obtained, reflecting the relationship between the curing degree and the reaction temperature and time.

$$
\alpha(t)=1-\left[1-1.58 \times 10^{4} \exp \left(-\frac{8.41 \times 10^{3}}{T}\right) t\right]^{11.11}
$$


Table 3. DSC exotherm peak temperatures of resin at different heating rates.

\begin{tabular}{ccccc}
\hline$\beta /\left({ }^{\circ} \mathbf{C} \cdot \mathbf{m i n}^{-1}\right)$ & $T_{p} / \mathbf{K}$ & $\mathbf{1} / \boldsymbol{T}_{\boldsymbol{p}}(\mathbf{1 0 0 0 / K})$ & $\ln \boldsymbol{l n}\left(\beta / \boldsymbol{T}_{\boldsymbol{P}}^{2}\right)$ \\
\hline 5 & 412 & 2.42 & 1.61 & -10.43 \\
\hline 10 & 427 & 2.34 & 2.30 & -9.81 \\
\hline 15 & 433 & 2.31 & 2.71 & -9.43 \\
\hline
\end{tabular}
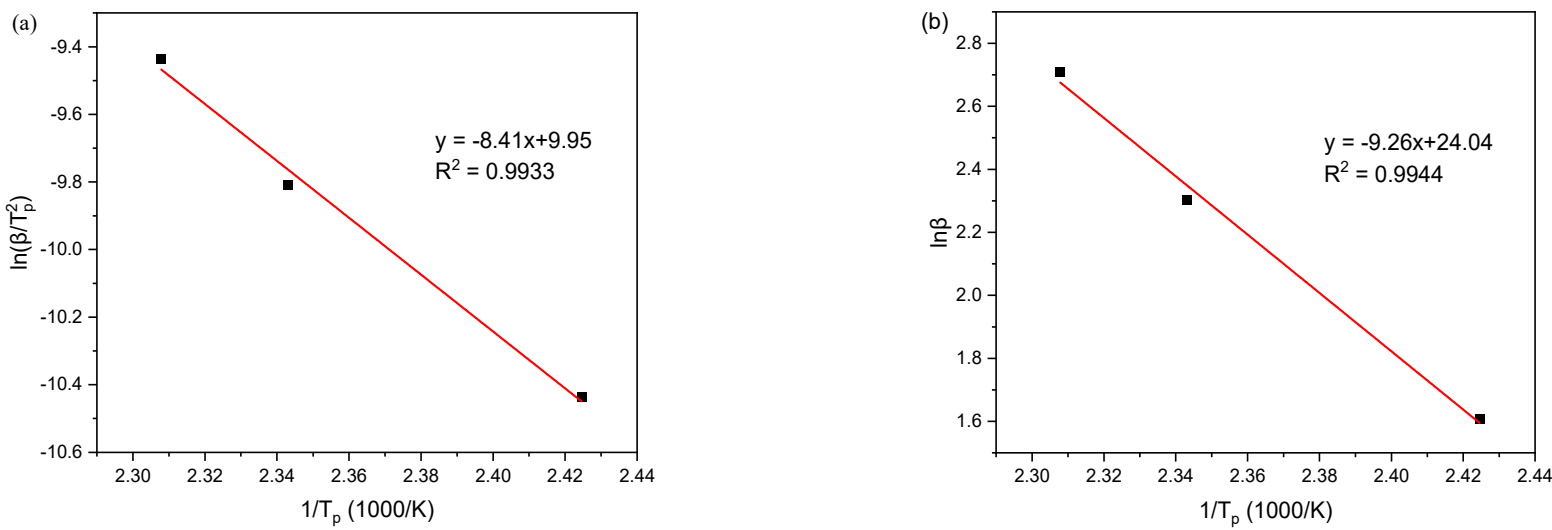

Figure 7. The fitting curve of (a) activation energy and pre-exponential factor; (b) reaction order.

Compared with other binders, this article uses a modified hybrid epoxy resin whose main components include aliphatic and cycloaliphatic resins. Similar research comparisons with other systems are shown in Table 4 . It is found that both the apparent activation energy $E_{a}$ and the reaction order $n$ are relatively small. In the resin system of this article, the apparent activation energy is relatively low. This may be because as the degree of curing increases, the free movement between molecular segments is less restricted, and the degree of freedom is higher, so more energy is not needed to overcome the energy barrier. The concentration of the resin system has a small effect on the reaction rate, so the reaction order is small.

Table 4. Comparison with similar studies of other systems.

\begin{tabular}{|c|c|c|c|}
\hline Type of Bender & $E_{a}(\mathrm{~kJ} / \mathrm{mol})$ & Reaction Order & Ref Number \\
\hline Bisphenol-A & 71.42 & 1.3435 & [31] \\
\hline TDE-85/BMAPF & 73.99 & 0.908 & [32] \\
\hline $\begin{array}{l}\text { Multifunctional } \\
\text { P-containing }\end{array}$ & 72.96 & 3.21 & [33] \\
\hline Phenolic & 96.03 & - & [34] \\
\hline VTM264 & 96.4 & - & [35] \\
\hline E51 & 102.55 & 1.3064 & [36] \\
\hline Epoxy & 88.549 & 1.323 & [37] \\
\hline $7901 \mathrm{DNK}$ & 69.95 & 0.91 & This work \\
\hline
\end{tabular}

\subsection{Bending Performance}

The load-displacement curves and three-point bending test data of the five samples are shown in Figure 8 and Table 5. The stress-strain curves of the samples increase linearly at the initial stage; after reaching the maximum strain, the bending stress suddenly drops, showing prominent brittle fracture characteristics. It is worth noting that before the maximum stress is reached, there is no obvious inflection point in the curve, indicating that the sample has not been significantly damaged before the final failure. 


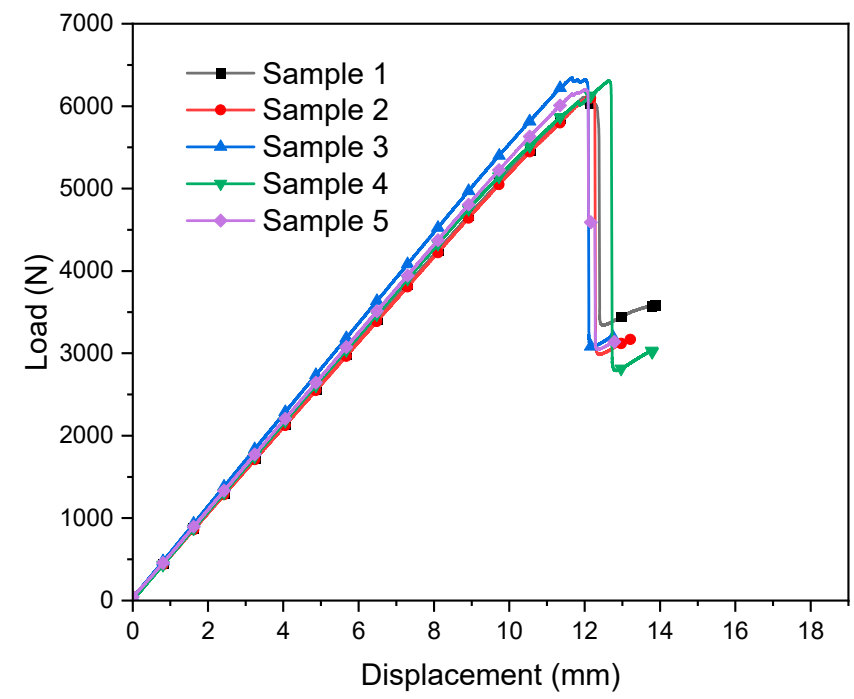

Figure 8. Load-displacement curve of E-glass fiber/epoxy composite samples.

Table 5. Three-point bending test data.

\begin{tabular}{ccccc}
\hline Sample & Load Time (s) & $\begin{array}{c}\text { Displacement } \\
(\mathbf{m m})\end{array}$ & Load (N) & $\begin{array}{c}\text { Flexural } \\
\text { Modulus (MPa) }\end{array}$ \\
\hline 1 & 96.93 & 16.82 & 6112 & 411 \\
\hline 2 & 75.72 & 13.22 & 6106 & 408 \\
\hline 3 & 72.95 & 12.76 & 6356 & 438 \\
\hline 4 & 79.21 & 13.79 & 6315 & 421 \\
\hline 5 & 74.34 & 12.99 & 6231 & 423 \\
\hline
\end{tabular}

Figure 9 shows the surface morphology of the sample after being destroyed. The damage of the specimen mainly occurs at the compressed place, as shown in Figure 9a, because the compressed place has the most significant displacement. When the load is generated, the epoxy resin is first subjected to the force, and then the force is transmitted to the glass fiber that plays the main force-bearing role. As the load increases, downward strain occurs at the compressed area, resulting in mutual extrusion. Epoxy resin has a poor ability to withstand force. It is first damaged and then crushed, leaving only a small part on the glass fiber, as shown in Figure 10a. When the stress reaches the maximum that the glass fiber can withstand, the glass fiber breaks; one end of the broken fiber continues to move downward under the squeeze of the upper indenter, pulling the fiber along the direction of the yarn, causing cracks to occur and expand. The cracks propagate to form different fiber bundles, as shown in Figure 10b. The failure mode of the sample is mainly manifested as the slippage and mutual extrusion of the fiber bundles, which is easier to be observed in the macroscopic view, as shown in Figure $9 \mathrm{~b}$. This is because the resin is tightly combined with the fiber and is not easily split into individual fibers.
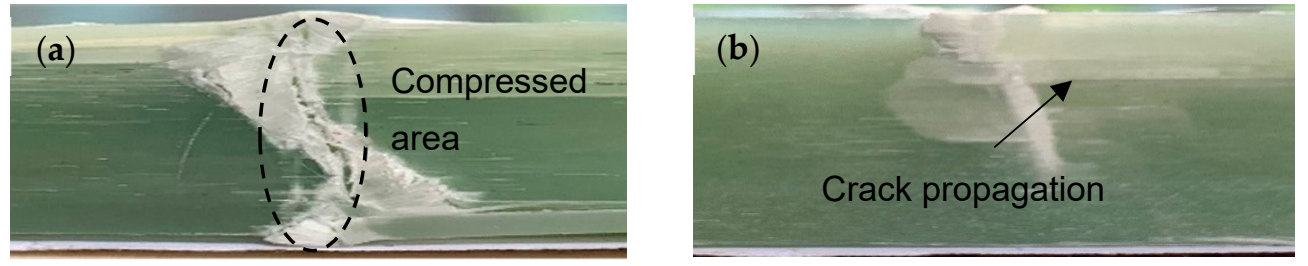

Figure 9. SEM images of fracture surface with (a) 500× magnification and (b) $80 \times$ magnification. 

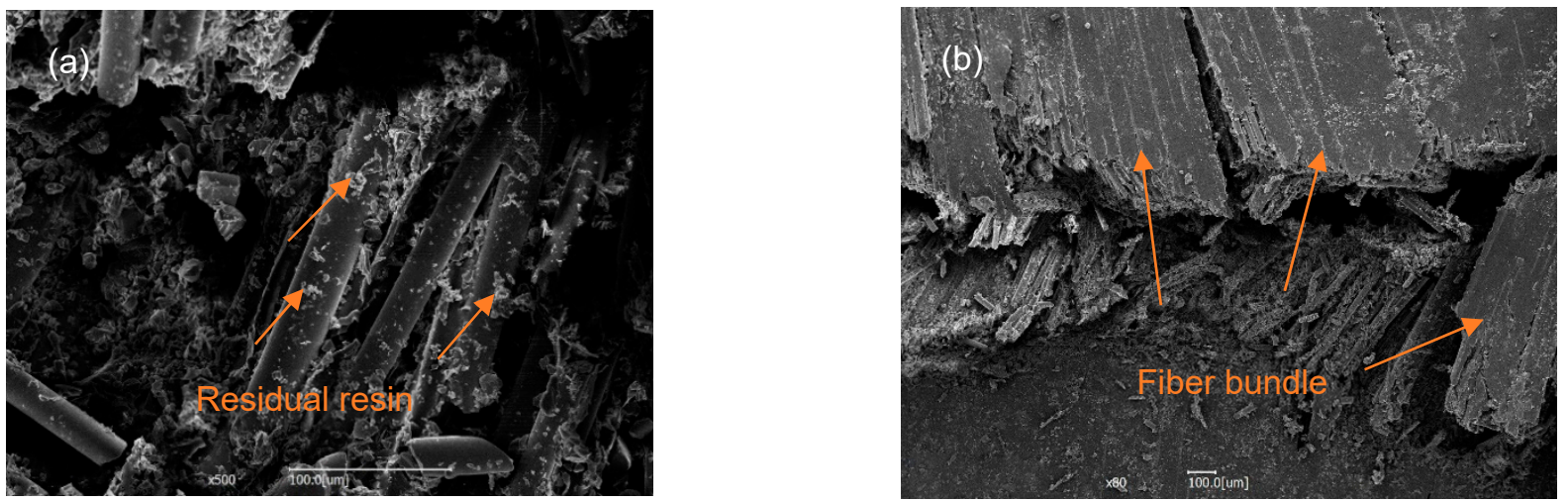

Figure 10. SEM photos of the fracture surface with (a) 500× magnification and (b) $80 \times$ magnification.

\section{Conclusions}

Herein, the cure kinetics of an E-glass/epoxy resin prepreg was investigated by DSC. The fracture behavior of the composite was studied by a three-point bending test, and surface morphology was assessed. The TGA analysis showed a stable thermal structure; the resin decomposes rapidly at about $350{ }^{\circ} \mathrm{C}$. DSC studies showed that the optimal pre-curing temperature, gel temperature, and post-treatment temperature of prepreg are 116, 130, and $153{ }^{\circ} \mathrm{C}$, respectively. Based on the Kissinger and Crane Equations, the apparent activation energy $E_{a}$ of the prepreg is $69.95 \mathrm{~kJ} / \mathrm{mol}$, the pre-exponent factor $\mathrm{A}$ is $1.76 \times 10^{5} \mathrm{~min}^{-1}$, and the reaction order $n$ is 0.91 . Finally, the $n$ th-order curing reaction kinetic equation of the prepreg is established. A three-point bending test was performed on the laminate sample. The results show that the difference in mechanical properties is relatively small, indicating that the laminate has fewer internal defects, stable quality, and reasonable curing temperature process design. The SEM photos also prove that the resin and fiber are tightly bonded.

Author Contributions: Conceptualization, L.Z. and Z.W.; methodology, L.Z.; software, Z.W.; validation, Z.W.; formal analysis, Z.W. and M.B.R.; investigation, Z.W.; resources, W.S.; data curation, Z.W.; writing—original draft preparation, Z.W.; writing—review and editing, L.Z. and M.B.R.; supervision, C.Z.; project administration, L.Z.; funding acquisition, L.Z. All authors have read and agreed to the published version of the manuscript.

Funding: This research was funded by Zhejiang Provincial Natural Science Foundation of China (LGG21E050025), Opening Project of Zhejiang Key Laboratory of Clean Dyeing and Finishing Technology, (QJRZ1907) and Fundamental Research Funds of Zhejiang Sci-Tech University, (20202113-Y).

Institutional Review Board Statement: Not applicable.

Informed Consent Statement: Not applicable.

Data Availability Statement: The data can be provided by the corresponding author on request.

Conflicts of Interest: The authors declare no conflict of interest.

\section{References}

1. Stickel, J.M.; Nagarajan, M. Glass Fiber-Reinforced Composites: From Formulation to Application. Int. J. Appl. Glass Sci. 2012, 3, 122-136. [CrossRef]

2. Yıldız, S.; Karaağaç, B.; Güzeliş, S.G. Utilization of Glass Fiber Reinforced Polymer Wastes. Polym. Compos. 2021, 42, 412-423. [CrossRef]

3. Islam, M.; Ar-Rashid, H.; Islam, F.; Karmaker, N.; Koly, F.A.; Mahmud, J.; Keya, K.N.; Khan, R.A. Fabrication and Characterization of E-Glass Fiber Reinforced Unsaturated Polyester Resin Based Composite Materials. In Nano Hybrids and Composites; Trans Tech Publications Ltd.: Pfaffikon, Switzerland, 2019; Volume 24, pp. 1-7.

4. Karvanis, K.; Rusnáková, S.; Žaludek, M.; Čapka, A. Preparation and Dynamic Mechanical Analysis of Glass or Carbon Fiber/Polymer Composites. In IOP Conference Series: Materials Science and Engineering; IOP Publishing: Bristol, UK, 2018; Volume 362, p. 012005. 
5. Budelmann, D.; Schmidt, C.; Meiners, D. Prepreg Tack: A Review of Mechanisms, Measurement, and Manufacturing Implication. Polym. Compos. 2020, 41, 3440-3458. [CrossRef]

6. Hou, J.P.; Cherruault, J.Y.; Nairne, I.; Jeronimidis, G.; Mayer, R.M. Evolution of the Eye-End Design of a Composite Leaf Spring for Heavy Axle Loads. Compos. Struct. 2007, 78, 351-358. [CrossRef]

7. Kim, H.G. Dielectric Cure Monitoring for Glass/Polyester Prepreg Composites. Compos. Struct. 2002, 57, 91-99. [CrossRef]

8. Du, S.; Guo, Z.-S.; Zhang, B.; Wu, Z. Cure Kinetics of Epoxy Resin Used for Advanced Composites. Polym. Int. 2004, 53, 1343-1347. [CrossRef]

9. Hardis, R.; Jessop, J.L.; Peters, F.E.; Kessler, M.R. Cure Kinetics Characterization and Monitoring of an Epoxy Resin Using DSC, Raman Spectroscopy, and DEA. Compos. Part A Appl. Sci. Manuf. 2013, 49, 100-108. [CrossRef]

10. Ma, H.; Zhang, X.; Ju, F.; Tsai, S.-B. A Study on Curing Kinetics of Nano-Phase Modified Epoxy Resin. Sci. Rep. 2018, 8, 1-15. [CrossRef]

11. Cai, H.; Li, P.; Sui, G.; Yu, Y.; Li, G.; Yang, X.; Ryu, S. Curing Kinetics Study of Epoxy Resin/Flexible Amine Toughness Systems by Dynamic and Isothermal DSC. Thermochim. Acta 2008, 473, 101-105. [CrossRef]

12. Liu, Z.; Xiao, J.; Bai, S.; Zhang, W. Study on Phenomenological Curing Model of Epoxy Resin for Prediction of Degree of Cure. J. Therm. Anal. Calorim. 2012, 109, 1555-1561. [CrossRef]

13. Mphahlele, K.; Ray, S.S.; Kolesnikov, A. Cure Kinetics, Morphology Development, and Rheology of a High-Performance Carbon-Fiber-Reinforced Epoxy Composite. Compos. Part B Eng. 2019, 176, 107300. [CrossRef]

14. Azzam, A.; Li, W. An Experimental Investigation on the Three-Point Bending Behavior of Composite Laminate. In IOP Conference Series: Materials Science and Engineering; IOP Publishing: Bristol, UK, 2014; Volume 62, p. 012016.

15. Mouzakis, D.E.; Zoga, H.; Galiotis, C. Accelerated Environmental Ageing Study of Polyester/Glass Fiber Reinforced Composites (GFRPCs). Compos. Part B Eng. 2008, 39, 467-475. [CrossRef]

16. Ren, D.; Li, K.; Chen, L.; Chen, S.; Han, M.; Xu, M.; Liu, X. Modification on Glass Fiber Surface and Their Improved Properties of Fiber-Reinforced Composites via Enhanced Interfacial Properties. Compos. Part B Eng. 2019, 177, 107419. [CrossRef]

17. Jariwala, H.; Jain, P.; Maisuriya, V. Experimental and Statistical Analysis of Strength of Glass Fiber Reinforced Polymer Composite for Different Fiber Architecture. Polym. Compos. 2021, 42, 1407-1419. [CrossRef]

18. Shin, P.-S.; Wang, Z.-J.; Kwon, D.-J.; Choi, J.-Y.; Sung, I.; Jin, D.-S.; Kang, S.-W.; Kim, J.-C.; DeVries, K.L.; Park, J.-M. Optimum Mixing Ratio of Epoxy for Glass Fiber Reinforced Composites with High Thermal Stability. Compos. Part B Eng. 2015, 79, 132-137. [CrossRef]

19. Memon, H.; Wei, Y. Welding and Reprocessing of Disulfide-Containing Thermoset Epoxy Resin Exhibiting Behavior Reminiscent of a Thermoplastic. J. Appl. Polym. Sci. 2020, 137, 49541. [CrossRef]

20. Xu, W.-B.; Bao, S.-P.; Shen, S.-J.; Hang, G.-P.; He, P.-S. Curing Kinetics of Epoxy Resin-Imidazole-Organic Montmorillonite Nanocomposites Determined by Differential Scanning Calorimetry. J. Appl. Polym. Sci. 2003, 88, 2932-2941. [CrossRef]

21. Yousefi, A.; Lafleur, P.G.; Gauvin, R. Kinetic Studies of Thermoset Cure Reactions: A Review. Polym. Compos. 1997, 18, 157-168. [CrossRef]

22. Garschke, C.; Parlevliet, P.P.; Weimer, C.; Fox, B.L. Cure Kinetics and Viscosity Modelling of a High-Performance Epoxy Resin Film. Polym. Test. 2013, 32, 150-157. [CrossRef]

23. Kratz, J.; Hsiao, K.; Fernlund, G.; Hubert, P. Thermal Models for MTM45-1 and Cycom 5320 out-of-Autoclave Prepreg Resins. J. Compos. Mater. 2013, 47, 341-352. [CrossRef]

24. Ferdosian, F.; Zhang, Y.; Yuan, Z.; Anderson, M.; Xu, C.C. Curing Kinetics and Mechanical Properties of Bio-Based Epoxy Composites Comprising Lignin-Based Epoxy Resins. Eur. Polym. J. 2016, 82, 153-165. [CrossRef]

25. Gonis, J.I.M.; Simon, G.P.; Cook, W.D. Cure Properties of Epoxies with Varying Chain Length as Studied by DSC. J. Appl. Polym. Sci. 1999, 72, 1479-1488. [CrossRef]

26. Yang, L.F.; Yao, K.D.; Koh, W. Kinetics Analysis of the Curing Reaction of Fast Cure Epoxy Prepregs. J. Appl. Polym. Sci. 1999, 73, 1501-1508. [CrossRef]

27. Kissinger, H.E. Reaction Kinetics in Differential Thermal Analysis. Anal. Chem. 1957, 29, 1702-1706. [CrossRef]

28. Tudorachi, N.; Mustata, F. Curing and Thermal Degradation of Diglycidyl Ether of Bisphenol A Epoxy Resin Crosslinked with Natural Hydroxy Acids as Environmentally Friendly Hardeners. Arab. J. Chem. 2020, 13, 671-682. [CrossRef]

29. Li, L.; Zou, H.; Liang, M.; Chen, Y. Study on the Effect of Poly (Oxypropylene) Diamine Modified Organic Montmorillonite on Curing Kinetics of Epoxy Nanocomposties. Thermochim. Acta 2014, 597, 93-100. [CrossRef]

30. Liu, Y.; Wang, J.; Xu, S. Synthesis and Curing Kinetics of Cardanol-Based Curing Agents for Epoxy Resin by in Situ Depolymerization of Paraformaldehyde. J. Polym. Sci. Part A Polym. Chem. 2014, 52, 472-480. [CrossRef]

31. Zheng, T.; Xi, H.; Wang, Z.; Zhang, X.; Wang, Y.; Qiao, Y.; Wang, P.; Li, Q.; Li, Z.; Ji, C. The Curing Kinetics and Mechanical Properties of Epoxy Resin Composites Reinforced by PEEK Microparticles. Polym. Test. 2020, 91, 106781. [CrossRef]

32. Liu, W.; Qiu, Q.; Wang, J.; Huo, Z.; Sun, H. Curing Kinetics and Properties of Epoxy Resin-Fluorenyl Diamine Systems. Polymer 2008, 49, 4399-4405. [CrossRef]

33. Hu, J.; Shan, J.; Wen, D.; Liu, X.; Zhao, J.; Tong, Z. Flame Retardant, Mechanical Properties and Curing Kinetics of DOPO-Based Epoxy Resins. Polym. Degrad. Stab. 2014, 109, 218-225. [CrossRef]

34. Chen, Y.; Wu, Y.; Geng, C.; Li, Z.; Dai, G.; Cui, W. Curing Kinetics and the Properties of KH560-SiO2/Polyethersulfone/BismaleimidePhenolic Epoxy Resin Composite. J. Inorg. Organomet. Polym. Mater. 2020, 30, 1735-1743. [CrossRef] 
35. Newcomb, B.A. Time-Temperature-Transformation (TTT) Diagram of a Carbon Fiber Epoxy Prepreg. Polym. Test. 2019, 77, 105859. [CrossRef]

36. Sun, H.; Liu, Y.; Wang, Y.; Tan, H. Curing Behavior of Epoxy Resins in Two-Stage Curing Process by Non-Isothermal Differential Scanning Calorimetry Kinetics Method. J. Appl. Polym. Sci. 2014, 131. [CrossRef]

37. Zhou, J.; Li, Y.; Cheng, L.; Zhang, L. Indirect Microwave Curing Process Design for Manufacturing Thick Multidirectional Carbon Fiber Reinforced Thermoset Composite Materials. Appl. Compos. Mater. 2019, 26, 533-552. [CrossRef] 